\title{
INMIGRACIÓN, SEGURIDAD Y DEMOCRACIA
}

\author{
IMMIGRATION, SECURITY AND DEMOCRACY
}

José J. Sanmartín

Universidad de Alicante. España/Spain

jose.sanmartin@ua.es

Recibido/Received: 24/11/2011

Aceptado/Accepted: 20/02/2012

\section{RESUMEN}

El presente artículo explora la relación entre seguridad e inmigración, desde la perspectiva de una sociedad democrática avanzada. El respeto debido a las leyes, el cumplimiento de las normas de convivencia, entre otros aportes, también ejerce un papel vertebrador favorable para la legitimidad democrática. Los inmigrantes como aportación positiva a la vivencia de libertad que son las sociedades plurales de Occidente.

\section{PALABRAS Clave}

Inmigración, seguridad, democracia.

\section{SUMARIO}

1. Introducción. 2. La seguridad como concepto empírico. 3. Legalidad y ciudadanía. 4. La dimensión transnacional. 5. Conclusiones. Bibliografía.

\section{ABSTRACT}

This article explores the link between security and migration, as a part of a progressive and democratic society. The needed respect for law enforcement, the compliance with the rules of coexistence, among other contributions, also play favorable roles for democratic legitimacy. Immigrants as a positive contribution to the experience of freedom that Western plural societies represent.

\section{KEYWORDS}

Migration, security, democracy.

\section{CONTENTS}

1. Introduction. 2. Security as an empirical concept. 3. Legality and citizenship. 4. The transnational dimension. 5. Conclusions. References.

"La seguridad es el complemento de la libertad, ó más bien es la libertad misma considerada en sus efectos prácticos y en sus resultados positivos". 


\section{INTRODUCCIÓN}

Desde una perspectiva sociológica, el vínculo, para algunos inextricable, entre inmigración y seguridad constituye, de entrada, uno de los aspectos perniciosos del tema. El mero planteamiento de la inmigración como un "problema" denota per se una actitud renuente, cuando no obstruccionista, al despliegue del potencial benéfico que los nuevos ciudadanos, que llegan, tienen para la sociedad de acogida. La diversidad per se, el aprendizaje de la convivencia en libertad, el intercambio de culturas, la mezcla de creencias, razas, lenguas y tradiciones, deben eclosionar en una democracia mestiza, también en el sentido político del término. El mestizaje como factor de cohesión, para compartir entre todos.

Al mismo tiempo, resulta imperativo el control de fronteras, al objeto, justamente, de proteger los derechos de los inmigrantes. La lucha contra las mafias, la erradicación de prácticas corruptas en el trámite inmigratorio, el reforzamiento del estatuto de ciudadanía además de la pura nacionalidad (el inmigrante deja de serlo inmediatamente, adquiriendo la condición de nuevo ciudadano en el país de acogida, asuma o no la nacionalidad de éste), son medidas encaminadas a lograr una interactuación entre nuevos y antiguos ciudadanos.

Que la inmigración es injustamente demonizada en tiempos de crisis, ha sido un mecanismo defensivo latente para minorías radicales y xenófobas. Es, precisamente, en estos últimos grupos donde anida la cultura de violencia, de la cual son víctimas tanto los nacidos dentro como fuera del país. La socialización del odio constituye un riesgo que avanza estridente unas veces, silente otras. La incultura política de un país queda igualmente denotada por la omnipresencia que los prejuicios ejerzan sobre el tejido securitario. Dicho de otra manera: los delitos cometidos por inmigrantes son explotados con fruición por parte de algunos medios de comunicación, sabedores de la alarma social que generan esas noticias entre segmentos determinados de población. Los miedos atávicos quedan activados en cada crisis de sensacionalismo acerca de "malestar entre los inmigrantes" o agresiones cometidas por un reducidísimo número de ellos (a veces, un solo infractor) en delitos comunes, de los que el público siente más cercanos. Pero no se hace referencia al magnífico comportamiento de la inmensa mayoría de nuevos ciudadanos que residen y trabajan en el país. Es preciso construir una cultura de convivencia que desarraigue los prejuicios todavía existentes, resultado del desconocimiento. En este sentido, el profesor José Asensi Sabater ha realizado una importante contribución en su obra Políticas de la sospecha, hasta el punto -altamente positivo- de reinterpretar la formulación del multiculturalismo:

"El multiculturalismo critica abiertamente el relativismo cultural (es decir, que cualquier cosa vale, con tal que sea "cultural", incluida la ablación clitoridiana, la humillación, la discriminación sexual o los castigos corporales) pero no por ello avala la tesis de que la cultura occidental sea el fin de los tiempos y el rasero con el que medir y comparar las diferencias: más bien afirma que todas las culturas son problemáticas frente a los derechos humanos y que, a la vez, en todas ellas cabe encontrar núcleos de eticidad" (Asensi Sabater, 2004:141).

\section{LA SEGURIDAD COMO CONCEPTO EMPÍRICO}

Tenemos estudios que examinan la relación entre seguridad e inmigración, así como su impacto sobre la sociedad de acogida (la de origen), el retorno, la reconstrucción del tejido 
familiar entre los migrantes, etc. El magnífico estudio de Myron Weyner conserva su vigencia por la calidad del análisis intelectual. Este autor no obvia las contradicciones intrínsecas que, en el seno de una democracia occidental, surgen alrededor de la proclamación de los Derechos Humanos, el acogimiento, el asilo, y demás figuras de humanitarismo, frente a los alineamientos restrictivos de la inmigración por motivos diversos (pero donde la seguridad, en sentido lato, ejerce como argumento cenital). Una política inmigratoria selectiva, por la cual el acceso a un Estado desarrollado occidental requiere del cumplimiento de un catálogo de requisitos, comporta límites; de tal manera, además (Weiner, 1992-1993:126) que

"would still leave large numbers of people banging on the doors, seeking to enter as refugees or, failing that, as illegals.

As alternative policy based upon the needs of immigrants and refugees, though morally more attractive, is more difficult to formulate, more difficult to implement, and legally and politically more contentious"

El "political realism" es para Weiner una perspectiva responsable para afrontar la interconexión entre Seguridad e inmigración; en esta coyuntura, la propia evaluación empírica de Weiner aporta un interesante desdoblamiento de lo que denomina "the security/stability framework", en el ámbito de los flujos migratorios de carácter internacional:

"The need for a security/stability framework for the study of international migration that focuses on state policies toward emigration and immigration as shaped by concerns over internal stability and international security. Such a framework should consider political changes within states as a major determinant of international population flows, and migration, including refugees flows, both as cause and as consequence of international conflict.

A security/stability framework can be contrasted with an international economy framework, which explains international migration primarily by focusing on global inegualities, the economic linkages between sending and receiving states including the movement of capital and technology and the role played by transnational institutions, and structural changes in labor markets linked to chages in the international división of labor" (Weiner, 1992-1993:94-95).

Sin embargo, como sostiene Emanuele Rossi, la distinción entre ciudadano e inmigrante no opera como fuente limitadora de derechos para estos últimos. A todos los efectos, y en base al artículo 2 de la Constitución italiana, la referencia a la persona que allí se hace debe interpretarse "alla persona in quanto tale, non essendo quindi differenze in ordine al possesso della cittadinanza" (Rossi, 2005:119). A mayor abundamiento, y buscando la precisión jurídica plena, el jurista italiano afirma que semejante conclusión

"resulta rafforzata dal principio di eguaglianza e di pari dignità sociale contenuto nell'art. 3 Cos.: principio che, come si è detto, debe ritenersi applicabile-malgrado il riferimento testuale ai "cittadini"- ad ogni persona. Sebbene infatti tale conclusione sia stata autorevolmente contestata da parte della dottrina, essa trova conforto sicuro nella 
giurisprudenza costituzionale”, como las sentencias del alto tribunal italiano n. 104/1969, n. 62/1994, n. 144/1970, n. 120/1967 (Rossi, 2005:119-120).

También es necesario verificar la relevancia que pudiera tener la relación inmigraciónseguridad en el ámbito democrático. Dicho de otra manera: pasar de una concepción bipolar a otra plural, donde los tres dimensiones queden relacionados entre sí, junto al resto de la sociedad, y como factores dinamizadores, no estáticos, de una comunidad que vive proactivamente en libertad. Nos parece errónea la vinculación excluyente que pudiera darse entre inmigración e inseguridad, como si el crecimiento de la primera fuese causa ineluctable de la segunda. La llegada de nuevos ciudadanos (pues son tales) a un país no queda sometida a los designios del determinismo más fatalista. En los años sesenta del siglo XX numerosos europeos del sur emigraban hacia el norte, y ello, salvo excepciones, no supuso una perdida de seguridad en las calles de Hamburgo, Londres, París o Basilea. La inmigración será lo que nosotros queramos que sea, pero no demonicemos un fenómeno humano que es necesario y globalmente positivo.

La diversidad, el aprendizaje a la convivencia en libertad, el intercambio de culturas, la mezcla de experiencias, la búsqueda de lo diferente, el encuentro del contraste, son también manifestaciones intrínsecamente democráticas. Una sociedad plural y multiétnica constituye la más fabulosa escuela de libertad de que pueda dotarse un país. Lo contrario arrastra al estrechamiento de miras, y de expectativas. Desde la Teoría Política, también se contempla la inmigración como un hecho beneficioso para el conjunto de la sociedad, en cuanto ésta crece como escuela de convivencia. "La inmigración es económicamente necesaria y culturalmente imprescindible y, en un país que ha sido tan cerril y rígido como el nuestro, es terapéutico recibir forasteros" (Roiz, 2002). El pluralismo como rasgo constitutivo de la democracia, por cuyo medio queda igualmente legitimada la sociedad que acoge inmigrantes con una actitud de generosidad cívica y solidaridad compartida.

Si la inmigración es indispensable para vivificar una economía desarrollada, no lo es menos para conferir dividendos a la misma práctica democrática. El respeto mutuo, la saludable convivencia de quienes creen y practican cosmovisiones distintas, la búsqueda constante de puntos de convivencia y, dicho claramente, el mestizaje en su más amplio sentido, son elementos benéficos que retroalimentan el crecimiento de tejido cívico, base fundacional y germinadora de una democracia que merezca tal nombre. Que la inmigración ha sido utilizada como arma política tanto como factor para estabilizar (o desestabilizar) a un ordenamiento institucional determinado, ha sido una realidad tangible a lo largo de la Historia. El caso significativo que aporta la Argentina es indicador de la importancia que las relaciones sociales de origen inmigratorio tienen en la expansión del sentimiento nacional y el arraigo de prácticas solventes en la Administración, así como en el conjunto de la sociedad. Mientras dispuso de atractivo para incentivar una fuerte inmigración a su territorio, Argentina fue un país en crecimiento. Los flujos inmigratorios señalaron los momentos históricos de plenitud para la vigorosa nación hispánica. Entre los principales atributos a favor de la inmigración eran "la seguridad inviolable dada á la persona y á la propiedad" (Alberdi, 1856:526). Seguridad y propiedad como fundamentos de un país edificado sobre el progreso.

"La seguridad prometida por la Constitución al poblador puede fallar por muchas causas: ó bien porque la Constitución carezca de leyes que la pongan en ejercicio; ó bien porque las leyes, en vez de reglar su ejercicio, la alteren y anulen; ó bien porque las leyes 
no se observen. De todos modos, toda causa de inseguridad lo es al mismo tiempo de despoblación, ó de embarazo á la inmigración de nuevos pobladores. Así, la buena legislación, la regularidad en la administración de justicia y la rectitud y energía de las autoridades son hechos que por sí solos hacen afluir la población en los países nuevos, que carecen de ella y abundan de subsistencias" (Alberdi, 1856:526).

La xenofobia emerge, por tanto, como lo que es: un comportamiento no sólo incivilizado sino también abiertamente antidemocrático. Sus ejercientes fundan su "argumentario" en patéticas ristras de prejuicios donde la irracionalidad y la incultura campan a su aire. Y ello, lamentablemente, dispone de numerosos -y penosos- antecedentes.

"Que así para la seguridad y conservación de aquellas provincias como para su engrandecimiento moral y material, de que también dependen su indefinida unión á la Metropoli y las mayores ventajas que han de reportarle, la única inmigración que les conviene y debe permitirse es la de la raza blanca” (Ponce de León, 1867:197).

Los adalides de posiciones ideológicas extremistas, claramente antiliberales, tensan la cuerda de la convivencia mediante el sofisma generalizador: si un inmigrante ha delinquido, como consecuencia estos radicales afirman que todos los inmigrantes son delincuentes. Semejante barbaridad, además de cometerse una injusticia, queda sostenida en base a la rentabilidad electoral que pueda tener. Lo grave del caso es que estos infundios disfrutan de enorme eco entre capas sociales determinadas. Y ello nos conduce a otro hecho que debemos afrontar: la falta de pedagogía sobre la convivencia realizada en España. Un problema reside en que un sector del país todavía cree vivir en una nación monocolor, monolingüe y monoideológica. Ese país hace tiempo que dejó de existir, incluso en lo oficial.

La siguiente generación (la que se educa ahora) puede deparar sorpresas en tanto coexisten colectividades acostumbradas a la diversidad y al trabajo, junto a otras que hacen de la desidia profesional y el prejuicio personal parte consustancial de su mentalidad. Tendremos una sociedad tolerante en sus elementos más proactivos, pero intransigente entre los adoctrinados en los tópicos del zafio radicalismo. De estos últimos cabe temer rebrotes racistas dada su elevada exposición a los manipuladores ideológicos y a su propia falta de criterio objetivo. Esa ausencia de ponderación de los hechos es correlativa al nuevo culto al irracionalismo que practican minoritarios pero emergentes grupos juveniles, cuyo primitivismo intelectual e ideológico, no augura un porvenir de tolerancia ilustrada en esta materia. La cohabitación de varias sociedades en una es resultado de una complejidad social apenas resuelta mediante la imposición de valores instituidos desde arriba. Típico defecto elitista de la democracia española, que se arrastra desde la Transición, resulta perentoria (ahora y desde hace tiempo) la necesidad de proveer de contenido real a los conceptos, haciéndolos vivificar en la experiencia del día a día. La socialización de la democracia como valladar frente a la xenofobia y el extremismo. Y es que la inmigración plantea un desafío a la misma noción de libertad que Occidente pueda detentar. De la formalidad a la realidad. La Europa de los Derechos Humanos está compelida a gestionar la diversidad de su nueva configuración social, y ello puede constituir una fuente primigenia de regeneración democrática -y ética-, de superarse las rémoras del prejuicio y el egoísmo. 
“L'Europe se découvre tardivement terre d'immigration: le passage d'une immigration de travail des années de croissance à une immigration d'installation suite à la fermeture des frontières s'est effectuée souvent douloureusement. La poursuite de l'arrivée clandestine de nouveaux arrivants est vécue comme une "invasión de pauvres" venant s'installer à la table des États providence, face à son impuissance à gérer ses frontières. Aucun pays du monde n'a d'ailleurs pour l'instant de réponse à court terme à la poursuite de l'immigration. De tous les éléments parfois contradictoires qui lui sont posés par cette nouvelle donne, la conviction dans l'opinion publique qu'il s'agit là d'un atout à saisir est sans doute le plus important" (Wihtol de Wenden 2006:134).

Llegará el momento en que dispongamos de senadores afro-españoles, diputados de origen latinoamericano, ministros de apellido eslavo, etc. También es España. Y el multilingüismo deberá afirmarse en el espacio público. A pesar de lo que consideran el irredentismo ultranacionalista, las otras lenguas españolas como el catalán, el vasco o el gallego, pueden florecer si la inmigración se gestiona adecuadamente. La extensión del uso de las lenguas territoriales a toda la Administración General del Estado debiera ser un principio de ese recorrido, pues la lengua no es bandera partidista de nadie, sino patrimonio compartido de todos. Sellos postales en los idiomas españoles, ventanillas multilingües en las capitales de provincia, impresos en los idiomas reconocidos como cooficiales en toda la AGE, serán, entre otros, elementos a tener presentes como base del desarrollo social y democrático.

\section{LEGALIDAD Y CIUDADANÍA}

La extensión del tráfico ilegal de personas en nuestro tiempo, aporta a la cuestión migratoria una dimensión securitaria que antes fue circunscrita por diferentes condiciones. La inmigración es también materia de derechos fundamentales, siendo así que la democracia constituye el indispensable contrapunto para evitar los abusos y los delitos que se cometen en este ámbito. Democracia en cuanto despliegue y afirmación del Estado de Derecho; democracia como fuente provisora de seguridad jurídica para el inmigrante. Y ello resulta singularmente pertinente en situación de una inducida nueva esclavitud a que crecientes segmentos de inmigrantes quedan sometidos por grupos delictivos de usos mafiosos. Por tanto, la armonización de conceptos es del todo indispensable para afrontar el combate contra esas mercantilizadas organizaciones criminales; la definición jurídica de contrabando de inmigrantes, tráfico de seres humanos o de inmigración clandestina, como señala el profesor Pérez Alonso, "redundará en un avance considerable en la lucha penal local y global contra esta nueva realidad criminal” (Pérez Alonso, 2008:151).

El aumento exponencial del tráfico de personas tiene su correlato en abusos y atropellos sin fin, atentatorios también de la dignidad de la mujer y de los menores. La dimensión transnacional de la inmigración ilegal obliga, desde hace años, a un planteamiento global del problema. Cumbres europeas, convenios internacionales, Conferencias sectoriales, entre otros formatos diplomáticos y políticos, han activado propuestas al objeto de atender un problema creciente (un solvente análisis de tales iniciativas, aparece en Iglesias Machado y Becerra Domínguez, 2007). Las tratativas internacionales suscritas contra el tráfico de personas, para la extinción de la esclavitud (mayormente con destino al comercio sexual), entre otros, son también materia securitaria 
en un Estado responsable y consciente de sus deberes cívicos. En este punto, Pérez Alonso ha argumentado la necesidad de reforzar el ejercicio de la potestad pública para impedir la trata y explotación subsiguiente de personas.

"El consciente abandono de funciones por parte de los poderes públicos es otro factor criminógeno importante que no se puede obviar; pues esta permisividad y dejadez de funciones públicas está contribuyendo al mantenimiento e incremento de esta situación atentatoria contra los derechos fundamentales de las personas víctimas de la trata o de su explotación posterior” (Pérez Alonso, 2009:436).

La única divisa posible en esta materia es el hostigamiento, enjuiciamiento y encarcelamiento para los explotadores, al tiempo que se dispensa acogida a las víctimas. Y aquí pueden aplicarse medidas contempladas en la Cuarta Conferencia Mundial sobre la Mujer (1995). La complejidad casi inextricable de las redes criminales que esclavizan a seres humanos, traficando con sus vidas en distintos países, fue desentrañada por Francisco Javier de León. Así, a la hora de explicar el papel desempeñado por el creciente número de organizaciones dedicadas a luchar contra la explotación,

"Otra muestra de la importancia de este fenómeno es el gran número de organizaciones que, durante los últimos años, se han ocupado del problema del tráfico de mujeres, si bien desde una óptica unilateral, ignorando su estrecha relación con otras prácticas de violencia sexual y explotación, específicamente el turismo del sexo, la prostitución militar, explotación sexual en Internet, la explotación laboral y la prostitución organizada, en cuya conexión encuentra pleno sentido el traslado transfronterizo de mujeres. Otro de los problemas del planteamiento inicial en el estudio de este problema por parte de estas organizaciones, que a la postres ha limitado su comprensión, ha sido la distinción de base entre la explotación sexual de adultos y menores y entre la llamada forzada y la voluntaria, llegando en la actualidad a la conclusión de que sólo la interconexión de todos estos factores permite un análisis aproximado sobre la actual industria del sexo, asentada en un marco socioeconómico que interactúa totalmente en la generación del tráfico. Se da la paradoja de que dichas distinciones a veces se han realizado en interés de la víctima, pero lo cierto es que, en ocasiones, sirven para proteger a la propia industria a costa de la víctima" (de León Villalba, 2003:317).

La privación de la condición de ciudadano está entre las primeras medidas que las mafias adoptan para sojuzgar a sus víctimas. Obviamente, la restauración de los derechos y libertades de que toda persona dispone, por el natural hecho de serlo, es una primera contramedida a implementar por los Estados democráticos. La cuestión no es baladí, sino piedra de toque para mantener limpia la propia conciencia de sociedad civil por parte de los países de acogida. Tengamos presente que la integración en un país de destino comporta asimismo un esfuerzo por parte del inmigrante, que debe acomodar sus valores a otra climatología de creencias, no siempre templada.

"Subyacente a la cultura democrática, a sus valores y prácticas, está la identidad ciudadana. Es un cúmulo de ideas, valores y prácticas compartidas que atañen, entre otros, a la representación de las formas jurídico-políticas del Estado como son el propio concepto 
de ciudadano, de ley, de autoridad, de justicia y verdad, de vida pública y vida privada, de persona, de separación entre Estado y religión, etc. La ley es garantía de libertad por cuanto sirve para todos por igual y todos debemos cumplirla por igual. La democracia no es pues únicamente un sistema jurídico-político sino un sistema cultural"; esto es, "además de las leyes y las instituciones legislativas, judiciales y políticas, sirve para fomentar y salvaguardar el pluralismo, la tolerancia y la igualdad de oportunidades" (Solé, 2011:177178).

Si esto acaece entre la inmigración legal, las variables se multiplican con las rutas de esclavitud impulsadas por organizaciones criminales, donde se trafica con la vida de personas a cambio de tangibles materiales; el absolutismo de lo inmoral. En este contexto, se ha producido un efecto contagio por el cual la inmigración ha sufrido los embates de crisis que le son ajenas. Así, las incidencias en el combate al terrorismo queda manifestado en una normativa cada vez más restrictiva para inmigrar. Como sostiene Townshend, casi siempre "más tentadora resulta la opción de modificar la legislación" (Townshend, 2008: 207). En la obra propositivamente iconoclasta de Giudicelli, al estudiar las revueltas de 2005 en los barrios parisinos de inmigrantes y descendientes, se concluye que "ningún gobierno se ha arriesgado, sin embargo, a establecer la relación política entre terrorismo, amenaza "interna" e integración" (Giudicelli, 2008:94). Entre la casuística activadora del radicalismo, aparecen señalados aquellos elementos también visibles entre grupos migrantes:

"Los principales factores -contexto y predisposición- favorables a esta "vulnerabilidad" son el conflicto identitario, el sentimiento de frustración experimentado respecto a las políticas gubernamentales y al racismo del que son objeto, al lugar que ocupan en la sociedad y a la fractura entre generaciones" (Giudicelli, 2008:72).

Son éstos ámbitos sobre los que resulta indispensable trabajar, pues en "los análisis de las evoluciones recientes de la violencia ponen de manifiesto un cambio en las razones del paso al acto, lo cual supone, en la actualidad, nuevos métodos de prevención y detección, e impone intervenir con mayor anticipación en ese proceso de radicalización" (Giudicelli, 2008:94-95). El extremismo es un hecho colateral -que no subyacente- entre los inmigrantes; de hecho, la mayor parte de éstos son personas con una actitud claramente constructiva en su aportación al país de acogida. Mayor contundencia y tendencia al sectarismo se da entre la población local, que -paradójica y significativamente- puede contaminar a elementos jóvenes de las comunidades de inmigrantes. Los "nuevos" fanáticos pueden ser resultado de la confusión de roles, dada la mezcolanza de una vivencia occidental junto a un adoctrinamiento oriental. La autoafirmación identitaria se plasma en un esencialismo que busca raíces desde el frenesí ideológico. Hasta ahora, la mayor parte de terroristas, incluso los declarados anti-occidentales, han tenido educación, formación o profesión en algún país democrático.

"Integration could consist of two different strands. First, a new and reinforced attempt to integrate the citizens of foreign origin into the society and assimilate the growing numbers of Muslims and citizens of other faiths. Second, new initiatives to induce legal, democratic, and economic reforms in countries that want close cooperation with the EU and the U.S. Thus, the U.S. and the EU could, for example, eliminate the flawed 
impression that they are anti-Muslim. They could reduce the support base for Islamist terrorist across the Muslim world" (Naumann, s.f.:145).

La integración en la sociedad de acogida no debe significar un acantonamiento en grupos de inmigrantes por características identitarias (origen nacional o étnico, filiación religiosa o laboral, etc.). Antes al contrario, lo recomendable es aplicar una estrategia de colaboración progresiva, mediante un sistema gradualista que escalone los pasos, eludiendo todo alineamiento abrupto. La participación de los inmigrantes, de esos nuevos ciudadanos, en la Cultura de Seguridad, puede reportar importantes dividendos favorables para el conjunto de la sociedad. De igual manera que a un Estado occidental le es inasumible unas fronteras abiertas por completo y de manera incondicionada a la inmigración, también resultaría igualmente contraproducente eludir nuestra responsabilidad para mejorar las condiciones de vida entre potenciales inmigrantes ya en sus países de origen. La ayuda (material, pero también securitaria) debe llegar desde la fase cero; directamente en los lugares de origen de los flujos migratorios. Los mecanismos de acción quedarán fijados en instrumentos de repatriación para inmigrantes ilegales y con antecedentes penales, y la posibilidad de expulsión para aquellos inmigrantes ilegales que incumplan la normativa del país de acogida, constatado mediante un sistema de puntos, junto a una eficiente cooperación al desarrollo, acuerdos de readmisión, protección de las fronteras, reagrupamiento familiar, contratos de ciudadanía y de residencia temporal para sectores concretos (a cambio, por ejemplo, de una formación recibida en el país de acogida para aplicarla en el país de origen), etc. Sí a la diversidad étnica y cultural como expresión prístina de riqueza para una sociedad moderna, pero no a la importación de redes delictivas, ni de prácticas que atenten contra los Derechos Humanos. Cada cual puede y debe vivir conforme a su identidad, pero aceptando unas reglas del juego que son las normas de convivencia de la sociedad de acogida. Cumplimiento estricto de las leyes del Estado que les garantiza derechos y libertades, además de mantener una identidad sumatoria y plural: ser también ciudadanos de un Estado de Derecho moderno y democrático.

La inmigración "implica la necesidad de ocuparse de garantizar a los extranjeros migrantes un mínimo de estatus jurídico de reconocimiento de derechos en el marco del ordenamiento jurídico del Estado. Es esta problemática la que ha determinado la actual actitud de los ordenamientos respecto al problema de la extranjería y la inmigración: considerarlo un problema de orden público, que puede afectar al núcleo de la misma soberanía del Estado” (Mayordomo Rodrigo 2008:25).

Asimismo, el respeto mutuo tiene una vertiente como imperativo categórico que afecta a todos por igual, siendo la normativa jurídica la que dilucide cualquier controversia. La necesaria y recomendable flexibilidad que pueda adoptarse en la interpretación de la norma, bajo ningún concepto puede significar trato de favor (o agravio comparativo) para unos ciudadanos respecto de otros. La propuesta de "pluralismo jurídico" tiene algún acomodo en casos generales donde no surjan prejuicios a terceros, pero también ofrece límites determinados por el constitucionalismo democrático de un Estado de Derecho.

"Uno stretto rapporto crearsi anche tra pluralism giuridico e multiculturalismo, in quanto il primo permette di tener conto nelle riforme giuridiche che riguardano gli immigrati del loro punto di vista, delle norme da loro applicate e delle strategie da loro elaborate per superare i conflitti con la cultura dominante. Senza considerare, poi, che il 
tipo di problemi che, sul piano giuridico e sociale, suscita la compresenza di norme, sanzioni, procedure differenti nelle società multiculturali occidentali” (Facchi 2001:41).

En este ámbito debe darse la reciprocidad: en materia de Seguridad de los inmigrantes, los Estados concernidos deben alcanzar acuerdos plenamente operativos para actuar en todo el recorrido de las rutas -legales o ilegales- al objeto de proteger la vida, y los derechos, de los migrantes. En particular, la inmigración clandestina deberá ser especialmente perseguida dada su gravísima afección a la dignidad de la persona; pero semejante hostigamiento legal, judicial y policial debe dirigirse contra las mafias, apoyándose en los testimonies de las víctimas del tráfico de personas (que pueden ser dispensados de toda responsabilidad e, incluso, beneficiarse de un permiso de residencia si declaran contra la explotación sufrida). Se trata de perseverar en el mantenimiento de la Seguridad como activo a favor de la integración de los inmigrantes en una sociedad democrática, de tal manera que también puedan aportar una fuente de riqueza y estabilidad para sus países de origen.

"The aim of any counter-terrorism strategy should be twofold. It should aim to prevent terrorist attacks and, since there is no guarantee for successful prevention, it must protect the citizens as much as possible and ensure the functioning of the state. The emphasis should be on prevention, which means that such a strategy should be proactive and not event driven" (Naumann, s.f.:144).

\section{LA DIMENSIÓN TRANSNACIONAL}

Como pondera Kicinger, la estrecha conexión entre "migration and security issues is one of the main reasons for slow development of the common migration policy at the EU level" (Kicinger, 2004:4). Se trata, pues, de procesos concomitantes, en tanto el avance hacia una Europa mejor queda umbilicalmente unido a la integración de políticas securitarias que consoliden una inmigración legal, con plenitud de derechos para quienes, libremente, emprendan ese camino.

"Estas organizaciones deben adquirir un alcance intracomunitario y su fin debe ser integrar los distintos Cuerpos y Fuerzas de Seguridad de los Estados miembros para una adecuada coordinación de sus actuaciones a escala nacional y comunitaria, así como una estructura organizativa dotada de los medios técnicos, humanos y presupuestarios necesarios para crear una auténtico espacio de seguridad europeo" (García Coso, s.f.:14).

Al mismo tiempo, y a tenor de la sentencia del Tribunal europeo de Primera Instancia sobre el caso Kadi (Sentencia Kadi vs. Consejo y la Comisión Europea, de 21 de septiembre de 2005), la doctrina emergente sostiene que "la eficacia de unas medidas restrictivas -como las contenidas en el reglamento comunitario denuncia (sic) por Kadi- no implica que el juez comunitario esté exonerado a aplicar el principio de tutela judicial efectiva. Al contrario, en el contexto del control jurisdiccional ejercido por el juez comunitario se deberá arbitrar algún mecanismo para conciliar las preocupaciones legítimas de seguridad y el disfrute real por parte del justiciable de un grado suficiente de sus derechos a lo largo del procedimiento. Es decir, en el ámbito de la lucha contra el terrorismo es necesaria -al igual que en otros ámbitos- la búsqueda de un equilibrio entre el 
objetivo de seguridad que se persigue y la protección de los derechos y libertades fundamentales. Las medidas de seguridad pueden limitar el disfrute de ciertos derechos sólo de forma proporcional y temporal para alcanzar el objetivo que persiguen" (Eugenia López-Jacoiste Díaz , 2011:163-164). Así, como indica Jimena Quesada, respecto del acuerdo indemnizatorio entre el Gobierno venezolano y varios etarras ante la Comisión Interamericana de Derechos Humanos (informe de admisibilidad número 37/06 aprobado el 8 de noviembre de 2006 en el marco de su $124^{\circ}$ período de sesiones),

"La negociación política, pese a todo, no debiera confundirse con el margen de negociación jurídica susceptible de ser utilizada en controversias sobre graves violaciones de derechos humanos [...]. Lo cual significa que, en ocasiones, no procederá admitir acuerdo alguno, dado que deberá imponerse una solución "ejemplar" guiada por el respeto de los derechos humanos que comportará una condena mediante sentencia sobre el fondo del asunto; $y$, en otras ocasiones, procederá "rebajar" el acuerdo alcanzado por las partes, para que se guarde un equilibrio entre la supuesta violación provocada y la compensación otorgada a las presuntas víctimas, ya que esa compensación habrá de ser "equitativa" y no desmesurada e insultante para la dignidad de otras personas afectadas" (Jimena Quesada 2008:198-199).

El profesor Avilés Farré, explica objetivamente la decantación que la teoría del control social aporta a la cuestión inmigratoria, pues una persona queda "menos expuesta a caer en la delincuencia cuanto más integrada se encuentra en su entorno, a través de un conjunto de valores compartidos que se transmiten en el seno de la familia, la escuela, el barrio y todo el tejido asociativo que en su conjunto conforma una comunidad" (Avilés Farré, 2005:257). En esta línea, la idea de codesarrollo reformulada por Sami Naïr tiene un claro potencial en cuanto implica al país de origen y al de acogida, en una relación de igual a igual, donde se produce el "restablecimiento progresivo de la libertad de circulación" (Naïr, 2010:676). Sin embargo, los "beneficiarios" del contrato de codesarrollo no podrán obtener un permiso de residencia o de trabajo estable en Francia. Ésta es una condición indispensable para luchar contra la fuga de talentos y para incitar a los estudiantes a poner al servicio de su país de origen las cualificaciones obtenidas en Francia" (Naïr, 2010:647). Sin embargo, los "beneficiarios" del contrato de codesarrollo no podrán obtener un permiso de residencia o de trabajo estable en Francia. Ésta es una condición indispensable para luchar contra la fuga de talentos y para incitar a los estudiantes a poner al servicio de su país de origen las cualificaciones obtenidas en Francia" (Naïr, 2010:647). Al mismo tiempo, Naïr propone que la política de "migraciones y codesarrollo debe adaptar las acciones a las necesidades de los países asociados, medir la evolución de los fenómenos sociales, apreciar la relación entre el coste y la eficacia de las intervenciones y evaluar los resultados" (Naïr, 2010:637). La integración de inmigrantes, la "movilidad controlada para los ciudadanos de los países que hayan suscrito acuerdos de codesarrollo" (Naïr, 2010: 642). La rúbrica de contratos de codesarrollo, son, entre otras, propuestas de Naïr para la implementación de una política inmigratoria que atienda de manera coherente una cuestión plural y compleja como pocas.

En el ámbito del Reino de España, y desde una perspectiva jurídica, la Ley Orgánica 11/2003, de 29 de septiembre, de medidas concretas en materia de integración social de los extranjeros, ya mereció tempranas objeciones: 
"Entre las deficiencias en la tipificación expresa del tipo delictivo, que continúan existiendo, conviene destacar que el hecho de que el delito de tráfico de personas se regule como un tipo abierto, conlleva una amplitud incriminatoria injustifica [sic], que genera una serie de dificultades interpretativas y es merecedora de críticas por afectar a las exigencias de los principios de legalidad y proporcionalidad. Por ello, he defendido que, aunque se trata de tipos abiertos, no cualquier acto que teleológicamente esté dirigido a potenciar la inmigración de personas puede considerarse típico. Se trata de un delito de peligro hipotético, exigiendo que como mínimo dichos comportamientos sean idóneos para incidir en el tráfico, afectando la dignidad tanto individual como del colectivo de extranjeros" (Pérez Cepeda, 2004:280).

Que los instrumentos legales y materiales al servicio del Estado de Derecho para combatir el tráfico de personas, puedan ser percibidos como limitadores incluso a derechos y libertades, resultaría sintomática de la confusión de roles, tan manida -y tan lesiva- en esta materia. La inmigración como fenómeno social es plenamente legítima, y ajena por naturaleza a los riesgos securitarios que sí acarrean las organizaciones criminales en el ejercicio ignominioso del tráfico de personas. Es preciso establecer una nítida definición, y diferenciación, entre las víctimas, de un lado, y los victimarios, de otro. También sobre la interpretación que se haga, desde la arbitrariedad latente o la legalidad vigente, de la norma ética, asumida y adaptada a las circunstancias en cada tiempo social.

"También podría ser calificado como un supuesto de error de prohibición el sujeto que yerra sobre la concurrencia de una causa de justificación, como puede ser el estado de necesidad. Sin embargo, en los delitos de tráfico de personas entendemos que resulta difícil la aplicación de dicha causa de justificación puesto que, al no proteger estos delitos las políticas sobre flujos migratorios sino la dignidad de los ciudadanos extranjeros, normalmente quien actúa pensándose que su conducta se encuentra justificada por encontrarse el sujeto pasivo en una situación de necesidad producto del hambre, la pobreza o los conflictos bélicos, no afectará al bien jurídico protegido, siendo atípica su contribución al hecho" (Guardiola Lago, 2007:324).

Aparte de que el carácter escasamente sofisticado de los mecanismos hasta ahora empleados para evaluar el grado de radicalización entre comunidades de origen inmigrante en países occidentales, ha demostrado lo arriesgado de extraer conclusiones demasiado generales.

"Last year, the AIVD wrote a report about what it called 2,500 neo-radicals out of 850,000 Muslims in The Netherlands. These neo-radicals were described as either wearing traditional Arabic clothing or western clothes, but for the purpose of deception. Such descriptions create stereotypes that cannot be corrected. Since the public at large cannot discriminate between neo-radicals and other Muslims in the same way the AIVD seems to be able to, these such reports seem to portray all Muslims as enemies and can in no way be helpful in winning the "hearts and minds" of the people, which, after all, seems to be an obvious objective of counter-radicalization" (de Graff, 2010:43).

La precarización en el status del inmigrante, al que se mantiene en semejante limbo, en situación precaria, es una línea contraproducente en el ámbito estrictamente securitario. La 
prevención del radicalismo exige afirmativos esfuerzos por parte de la sociedad, y del Estado, de acogida. Tengamos presente que la utilización justificativa de la política discriminatoria constituye un efecto pernicioso en la acción de un Gobierno que pretenda el aseguramiento de la paz pública.

"Estas organizaciones criminales suelen actuar en solitario y en su entorno de actuación local. Sin embargo, en sus actividades internacionales y transnacionales, pueden también actuar formando alianzas puntuales con otras organizaciones para determinados servicios" (Giménez-Salinas Framis, 2008:211).

La misma Patricia Laurenzo Copello señala el predominio del enfoque trafiquista, "que reduce el complejo fenómeno de las migraciones económicas a una dicotomía simplista entre buenos -los migrantes- y malos -todo el que interviene para facilitar el traslado clandestino-. Una perspectiva hecha a la medida de los Estados hegemónicos que, tras despojar a los inmigrantes de autonomía y racionalidad, se arrogan la potestad de decidir qué es lo mejor para ellos, de ordenar un desorden del que se les declara víctimas inocentes" (Laurenzo Copello, 2008:238).

\section{CONCLUSIÓN}

La politización de una cuestión tan sensible, beneficiosa y relevante como la inmigración produce efectos perniciosos. El planteamiento humano y técnico a la vez, combinando lo deseable con lo posible, mas rebasando siempre esa ecuación en sentido positivo, es la clave para integrar a inmigrantes en una sociedad de acogida. Integración, bien entendido, que no puede suponer suplantación identitaria, mas empero suma constructiva de lo que se es y de lo que se siente. No se debe exigir, en modo alguno, a los inmigrantes que dejen de ser, pensar o creer en sus valores, sino que se acomoden a la sociedad de acogido, en el grado de pertenencia que mejor estimen, pero respetando en todo momento las normas locales de convivencia y, por supuesto, sus leyes. El desarraigo es mayor riesgo potencial como fuente de radicalismo y, consecuentemente, de violencia latente. Es conveniente que la integración se aplique como concepto flexible, exigiendo únicamente el cumplimiento de una base común que vincula a todos los ciudadanos por igual (con independencia de su lugar de nacimiento).

Entre las fuentes activadoras (que no necesariamente legitimadoras) de malestar social figura la desatención de los problemas que sufren los nuevos ciudadanos, de origen extranjero. La marginalidad laboral, el fracaso escolar, la falta de medios en sus barrios, inciden, junto a otras causas, también inciden sobre la todavía mejorable relación con la sociedad de acogida. La generalización culpabilizadora respecto de quienes son mantenidos permanentemente bajo la condición de inmigrantes, es ya de por sí una actitud nociva para el mismo desarrollo democrático. Un error contumaz ha sido culpar a los inmigrantes de las revueltas sociales en Europa, haciéndolos responsables de las algaradas, con visos de rebelión, desatadas en ciudades de Francia y otros países. Sin embargo, debe tenerse en cuenta que los inmigrados han permanecido en paz ciudadana durante esos altercados, siendo los descendientes ya europeos de antiguos inmigrantes los activadores de una protesta contra una situación de marginalidad frente a la que se rebelan. 
La percepción que tenga una opinión pública es una verdad parcial y, en ocasiones, no siempre correcta. Sin embargo, esas impresiones volátiles que componen la seguridad subjetiva no concuerdan con la precisión técnica de la seguridad objetiva, que suele proveer de mayor solvencia como constatación de la realidad. La existencia de prejuicios afecta incluso a la hora de la definición, y propalación, de los tipos penales. Así, en lo referido a inmigración ilegal, "en los que, por su simple descripción, parecería razonable hablar de delincuencia organizada, puesto que se percibe capacidad de infiltración en entidades estatales -uno de los rasgos distintivos de las mafias- cuando se trata de ciudadanos españoles no sólo no se menciona la nacionalidad de los autores sino que se emplea el término más inofensivo de red, en lugar del de banda, mafia o grupo organizado" (Rubio Pardo, s.f.:4).

El maniqueísmo aplicado, de facto, sobre las políticas securitarias demuestra las contradicciones de semejante alineamiento también en el ámbito de la inmigración. La exigencia de resultados tangibles sin dotar de medios legales y recursos materiales suficientes es del todo quimérico, aparte de contraproducente para afrontar los retos de una defensa eficiente del Estado democrático. Y tan loable objetivo dispondrá de un firme asidero una vez se canalice el formidable potencial de colaboración, e información, que las comunidades inmigrantes pueden aportar. El mismo Espacio de Libertad, Seguridad y Justicia de la Unión Europea contribuye a este respecto, pero faltan decisiones políticas en este camino, que es el de todos: la seguridad y la democracia.

\section{BIBLIOGRAFÍA}

ALBERDI, J. B. (1856), Organización política y económica de la Confederación Argentina. Besanzon: Imprenta de José Jacquin.

ASENSI SABATER, J. (2004), Políticas de la sospecha. Migraciones internacionales y principios constitucionales. Valencia: Tirant lo Blanch.

AVILES FARRE, J. (2005), "Las amenazas globales del siglo XXI", Arbor, n 709, tomo CLXXX.

AVILÉS FARRE, J. (2011), www.almendron.com/tribuna/23085/el-impacto-de-la-inmigracionsobre-la-seguridad- ciudadana/fecha de consulta: 26 de septiembre de 2011.

BOS DE GRAFF (2010), "The Overly-Broad Approach in Dutch Counter-Radicalization”, en Boaz G. y Eitan A. (eds.), The Global Impact of Terrorism 2008. Herzliya (Israel): The International Institute for Counter-Terrorism.

CANCIO MELIA, M. (2008), Política criminal en vanguardia: inmigración clandestina, terrorismo, criminalidad organizada. Cizur Menor (Navarra): Thompson-Civitas.

CARRERA HERNÁNDEZ, F. J. (1999), El espacio de libertad, seguridad y justicia en la Unión Europea: textos fundamentales: actos en materia de asilo, inmigración, cruce de fronteras, Europol, cooperación judicial penal, cooperación aduanera, acuerdos de Schengen. Madrid: Editorial Tecnos.

DE LEÓN VILLALBA, F. J. (2003), Tráfico de personas e inmigración ilegal. Valencia: Tirant lo Blanch.

FACCHI, A. (2001), I diritti nell'Europa multiculturale. Pluralismo normativo e immigrazione. Bari/Roma: Editori Laterza.

GARCÍA COSO, E. (s.f.), "Los avances de la UE contra el crimen organizado, tráfico de personas e inmigración ilegal", Instituto Universitario de Investigación sobre Seguridad Interior.

GIMÉNEZ-SALINAS FRAMIS, A. (2008), "Las organizaciones dedicadas a la inmigración ilegal y tráfico de seres humanos", en Cancio Meliá, M. y Pozuelo Pérez, L. (coords), Política criminal en vanguardia. Inmigración clandestina, terrorismo, criminalidad organizada. Cizur Menor: Thompson Civitas. 
GUARDiOla LAGO, M. J. (2007), El Tráfico de Personas en el Derecho Penal Español. Cizur Menor (Navarra): Thompson Aranzadi.

GUIDICELLI, A. (2008), El riesgo antiterrorista. Madrid: Foca Ediciones.

IGLESIAS MACHADO, S. y BECERRA DOMÍNGUEZ, M. (2007), La inmigración: el reto del siglo XXI. Madrid: Dykinson.

JIMENA QUESADA, L. (2008), Dignidad humana y justicia universal en España. Cizur Menor: Editorial Aranzadi.

KAZMIERKIEWICZ, P. (ed.) (2004), Securing America and Europe. Varsovia: Institute of Public Affairs.

KICINGER, A. (2004), "International Migration as a Non-Traditional Security Threat and the EU Responses to this Phenomenon", Varsovia, Central European Forum for Migration Research Working Paper, número 2/2004.

LAHAV, G. (2003), "Migration and Security: The Role of Non-State Actors and Civil Liberties in Liberal Democracies", paper: Second Coordination Meeting on International Migration UN, Nueva York.

LAURENZO COPELLO, P. (2008), "El modelo de protección penal de los inmigrantes de víctimas a excluidos", en Cancio Meliá, M. y Pozuelo Pérez. L. (coords), Política criminal en vanguardia. Inmigración clandestina, terrorismo, criminalidad organizada. Cizur Menor, Navarra: Thompson Civitas.

LÓPEZ-JACOISTE DÍAZ, E. (2011), “Terrorismo internacional y derechos humanos: El delicado equilibrio entre seguridad y libertad", en Gutiérrez Espada, C. (Director) y Cervell Hortal, M. J. (coords), Derecho Internacional, Alianza de Civilizaciones y terrorismo global. Murcia: Diego Marín Librero/Editor.

MAYORDOMO RODRIGO, V. (2008), El delito de tráfico ilegal e inmigración clandestina de personas a la luz de los textos internacionales. Madrid: Iustel.

MIR PUIG, S. y CORCOY BIDASOLO, M. (dirs,) (2009), Protección penal de los derechos de los trabajadores: seguridad en el trabajo, tráfico ilegal de personas e inmigración clandestina. Madrid: Edisofer.

NAÏR, S. (2010), La Europa mestiza. Inmigración, ciudadanía, codesarrollo. Barcelona: Galaxia Gutenberg / Círculo de Lectores.

NAUMANN, K. (s.f.), "The Role of the Military in Fighting Terrorism - a European View”, en Boaz G. y Eitan A. (eds,), Trends in International Terrorism and Counter-Terrorism. Herzliya (Israel): International Institute for Counter-Terrorism.

PÉREZ ALONSO, E. (2008), Tráfico de personas e inmigración clandestina (un estudio sociológico, internacional y jurídico-penal). Valencia: Tirant lo Blanc.

PÉREZ ALONSO, E. J. (2009), "Consideraciones político-criminales sobre el fenómeno migratorio actual y el tráfico de personas”, en Mir Puig, S. y Corcoy Bidasolo, M. (2009) Protección penal de los derechos de los trabajadores. Seguridad en el trabajo, tráfico ilegal de personas e inmigración clandestina. Madrid: Edisofer Libros Jurídicos, pp. 409-452.

PÉREZ CEPEDA, A. I. (2004), Globalización, tráfico internacional ilícito de personas y derecho penal. Granada: Editorial Comares.

PI LLORENS, M. (2010), ¿Hacia una Europa de las personas en el espacio de libertad, seguridad y justicia? Madrid: Marcial Pons.

PONCE DE LEÓN, N. (1867), Información sobre reformas en Cuba y Puerto Rico. Nueva York: Imprenta de Hallet y Breen, tomo I.

ROIZ, J. (2002), "Entrevista: Javier Roiz", El Siglo de Europa, número 513, disponible en: $\mathrm{http} / /$ www.elsiglodeuropa.es/siglo/historico/Pensamiento/pens2002/pensamiento513.htm Fecha de consulta: 28 de septiembre de 2011.

ROSSI, E. (2005), “I diritti fondamentali degli stranieri irregolari”, en Revenga Sánchez, M. Problemas constitucionales de la inmigración: una visión desde Italia y España. Valencia: Tirant lo Blanch.

RUBIO PARDO, M. (s.f.), "Inmigración irregular y crimen organizado en España”. Madrid: Instituto Universitario de Investigación sobre Seguridad Interior. 
SALT, J. (2001), Current Trends in International Migration in Europe. París: Consejo de Europa. SOLÉ, C, (2011), "Ciudadanía e integración", en VVAA, El desafío de la inmigración. Valencia: Grupo Valenciano del Capítulo Español del Club de Roma.

TORRY, H. (s.f.), "Migration and Security in SOA", Business Solutions Inc / University of Leeds TOWNSHEND, Ch. (2008), Terrorismo. Madrid: Alianza.

VVAA (2001), La gestión de la seguridad en las sociedades multiétnicas. Madrid: Dirección General de la Policía / Comisión Europea.

WEINER, M. (1992-1993), "Security, Stability, and International Migration”, International Security, Vol. 17, No. 3, pp.91-126.

WIHTOL DE WENDEN, C. (2006), “L’Union européenne et les enjeux migratoires”, en VVAA: La inmigració: una oportunitat? Andorra: Govern d'Andorra (Ministeri d'Habitatge, Joventud, Ensenyament Superior i Recerca), pp.125-134.

\section{Breve currículo:}

\section{José J. Sanmartín Pardo}

Profesor Titular de Ciencia Política y de la Administración en la Universidad de Alicante. Seagram International Fellow de la McGill University en 1999, Accésit al Premio de Estudios Parlamentarios en 2009 por la Fundación Giménez Abad, Doctor en Filosofía por la Universidad de Murcia, Doctor en Ciencia Política y Sociología por la UNED, Máster en Gestión y Análisis de Políticas Públicas por la Universidad Carlos III de Madrid, y Máster en Derecho de la Unión Europea por la UNED, entre otros. Autor de Circa 1900. El parlamentarismo como práctica liberal en España e Italia (monografía, 2010), "Los alquimistas del mal. Servicios de Inteligencia frente al terrorismo global" (artículo, 2009), junto a otros. 